\title{
Young Indian Entrepreneurs: A Multi-Criterion Decision Scenario
}

\author{
Surjit Kumar Kar' ${ }^{1}$, Saroj Kanta Biswal ${ }^{2}$ \\ ${ }^{1}$ Department of Marketing \& Strategy, IBS Hyderabad, Hyderabad, India \\ ${ }^{2}$ Faculty of Management Sciences, Siksha 'O' Anusandhan, Bhubaneswar, India \\ Email: surjitk@ibsindia.org, sarojkantabiswal@soa.ac.in
}

How to cite this paper: Kar, S.K. and Biswal, S.K. (2019) Young Indian Entrepreneurs: A Multi-Criterion Decision Scenario. Theoretical Economics Letters, 9, 1615-1632.

https://doi.org/10.4236/tel.2019.95103

Received: May 5, 2019

Accepted: June 23, 2019

Published: June 26, 2019

Copyright ( 2019 by author(s) and Scientific Research Publishing Inc. This work is licensed under the Creative Commons Attribution International License (CC BY 4.0).

http://creativecommons.org/licenses/by/4.0/ (c) () Open Access

\begin{abstract}
Entrepreneurship ventures are not new to India. They have been instrumental in developing the socio-economic scenario in the country. Many leading business houses today in India were family enterprises in their days of beginning. The latest trend is that India is reaping dividend because of larger percentage of youth in its population, who are venturing into innovative startups. With startups coming up in large numbers, Indian employment scenario is changing very fast. An entrepreneur starts a venture with her own will and might, and thus there are many important factors in such drive. A budding entrepreneur can come from any walk of life. However, a trained technical and/or managerial person may make a difference. Encountered with a challenging situation, a budding entrepreneur often finds himself at cross roads in her journey of life. This paper explores entrepreneurial narratives and classifies them into multi-criterion decision scenario faced at an individual level by an entrepreneur. Following a qualitative-quantitative research (mixed) approach, the paper shows outcome across two stages. Using qualitative research methods (e.g. Focus Group Discussion), a list of factors affecting motivation of someone to start an enterprise (called "startup") is obtained. Subsequently, an analytic hierarchy process (AHP) model has been used under quantitative paradigm. This approach used Decision Analysis Module for Excel (DAME) add-in on MS-Excel to analyze responses obtained on the aforesaid list of factors from subjects with entrepreneurial mindsets. It was found that the risk taking ability depends on situation a youth is facing. However, turbulence in socio-economic environment diminishes the risk appetite. Strategic option such as "Focus" which is one when barriers to entry are higher and very select competitors can get into the spectrum; and it is better coupled with low exit barrier for a fail-safe and fast-exit plan.
\end{abstract}




\section{Keywords}

Startup, Entrepreneurship, AHP, DAME

\section{Introduction}

The Government of India (GOI) has initiated institutionalized mechanisms through its various Ministries and Departments [1] to foster growth of innovation and entrepreneurial eco-system in the country. Demographic dividend of India (Median age in India will be: 28, China \& US: 37, Western Europe: 45, Japan: 49 by 2020) [2] is favorable and India has a large innovation potential [3]. Government is playing the role of a catalyst (13730 No. of startups recognized and 129 No. funded as on Nov 1, 2018) [4]. Startups are funded by providing access to loans, networks, markets and trainings [5]. Startup India, Make in India, Atal Innovation Mission (AIM), Atal Tinkering Labs (ATL), Atal Incubation Centres (AICs), Support to Training and Employment Programme for Women (STEP), Biotechnology Industry Research Assistance Council (BIRAC), Stand-Up India, Trade related Entrepreneurship Assistance and Development (TREAD), Pradhan Mantri Kaushal VikasYojana (PMKVY), National Skill Development Mission, Science for Equity Empowerment and Development (SEED) [6] etc. are some of the promising initiatives by the GOI. Six types of startups are prevalent in India at present e.g. Lifestyle Startup, Small family business, Scalable startups, Startups to be sold \& flipped, Large company startups, and Social startups [7]. Given the kind of eco-system development initiatives undertaken by facilitators $\&$ regulators in India, it becomes an area of concern to explore entrepreneurial mindset of Indian youth and their reasons to participate in the drive. Various socio-psychological dimensions along with their personality traits like risk taking or risk aversion attitude need to be explored. Entrepreneurship can provide a major source of employment creation, innovation and social adjustment for a developing economy [8] like India. As there is much thrust given by the government of India to help youth exploit and unleash their potential in entrepreneurial ventures, a study which can assess the mindsets of the target groups of such schemes and programs becomes important. This study used a mixed research design and concluded with hierarchy of alternative scenarios as it would be preferred by the budding entrepreneurial young class in the summary.

\section{Literature Review}

"Entrepreneurship" is a well-studied phenomenon with a common appeal across various domain areas and hence, the available literature comes from various discipline such as psychology, strategy, business management, public policy etc. The body of knowledge in this area of study seems very much scattered. "Entrepreneurs" are people who habitually create and innovate to build something of recognized value around perceived opportunities [9]. Different researchers have 
studied different dimensions of Entrepreneurship. Rohrbach [10] has studied initial funding and mentoring [11] [12] have focused on personality \& inter-generational differences. Giorgi and Marsh [13] and Furnham [14] have studied vocational work ethic and internal locus of control; Winfield [15] and Chell [16] have studied inter actionist or contingent model. Fagenson [17] has studied gender differences, whereas Cassidy and Lynn [18] and Markman and Baron [19] have studied constructs like need for achievement, internal locus of control, tolerance of ambiguity, type A behavior etc. There are various theories and models proposed by various researchers. McClelland [20] [21] believes that specific distinctive competences exist in some developing countries. Koh [22] and Gurol and Atsan [8] have related innovativeness and entrepreneurship. Tajeddini \& Mueller [23], Mueller [24], Liles [25], Hisrich and Brush, [26], Hatak et al. [27] and Fung et al. [28] debate over entrepreneurial character/traits as predictor to engage in entrepreneurship. Deakins \& Freel [29], Mahadea [30], Entrialgo, Fernandez \& Vazquez [31], McCllel and [20], Cromie [32] and Littunen [33] believe that distinct individual personality attributes (e.g. traits, age, experience, self-confidence, emotional \& psychological risks, and capacity) and entrepreneurial success are related. However, trait approaches have been criticized by Kristiansen \& Indarti [34], Krueger, Reilley \& Carsrud [35] and Keeley et al. [36]. Researchers like de Wit and van Winden [37], Taylor [38], Crant [39], Dolton and Makepeace [40], and Evans and Leighton [41] have propounded parental and family support models in entrepreneurship research. Gibb and Ritchie [42] have focused on social development model and Miller and Friesen [43] on contingent model. Social learning theory [44] bridges the behaviorists and the cognitivists focusing on imitation and learning through observation.

Startup or for that matter even family-run businesses are not new in Indian society. The high demographic dividend of India (youth comprising a higher percentage in population) in recent times is paying off and a rise of startup culture is noticed in India. The latest trend is that a graduate or even a school/college dropout wants to experiment entrepreneurship with her own idea of a business venture. Such inner drive in a youth (or millennial) brings in many individual personality factors into action e.g. motivation, need for achievement, leadership etc. Basing the previous researches and various dimensions studied so far, the present study mainly focuses on the learning through observation view in entrepreneurship and the intra-personal dimensions of decision making through personality and trait theory. This orientation of the current paper helps in identifying the inner strength of young entrepreneurial class in India with a subjective view amid changing socio-economic scenario, learning from positive cues in the environment and risk appetite as a part of personal attribute.

\section{Research Methodology}

This paper uses a mixed research approach combining both qualitative and quantitative paradigms. Following a qual-quant (mixed) research approach, the 
paper gathers outcome across two stages:

1) By using qualitative research methods e.g. Focus Group Discussion (FGD) a list of factors affecting motivation of someone to start an enterprise (can be called "startup") was generated and

2) By using an Analytic Hierarchy Process (AHP) model [45] based on responses on these factors drawn from subjects with entrepreneurial mindsets. The data gathered was then subject to DAME (Decision Analysis Module for Excel) add-in on MS-Excel [46] platform.

\subsection{Stage-1: Analysis}

Each of the two parts in the study has specific but related outcome. In the first study, a group of entrepreneurs drawn from different business domain (identities concealed upon request, $n=8$ ) were identified from close contacts and were approached for a Focus Group Discussion. The criteria of selection was that the participants:

- Should have started a venture/enterprise [47] in last two years of time, and that the venture must be operational without close down before the survey was conducted.

- The founder member/executive must be available to interact frequently with researcher for helping the researcher gather the right perspective.

The FGD was moderated by the researcher, and for anonymity, the list of participants is not furnished anywhere in the paper. The thematic codes \& categories of the discussion transcripts gave rise to a comprehensive list of items variables as shown in Appendix A [48]. Method of thematic coding was followed.

After a thoughtful deliberation by the researcher, few domain experts \& volunteering entrepreneurs, a questionnaire was prepared from the codes obtained from the transcript. An online survey $(n=290)$ was conducted to gather responses from Indian youth on a 5 -point Likert scale (where, $1=$ Strongly Disagree, 5 = Strongly Agree) on affirmative statements. The responses were put into a Principal Component Analysis (PCA) method to reduce the items into broad factors and name them. In this Exploratory factor Analysis (EFA), correlation and sampling adequacy were checked. KMO Measure of Sampling Adequacy was found 0.947 (>0.700), and multicollinearity among items checked through Bartlett's Test of Sphericity (Approx. Chi-Square: 10305.758, df: 666, Sig.0.000) was found significant ( $\mathrm{p}$-value $<0.05$, i.e. "H0: There is no multicollinearity" is rejected). This indicated that there is sufficient correlation to conduct factor analysis. In Anti-image Correlation matrix, no diagonal element value was found $<0.6$ (all were found $\geq 0.6$ ) indicating adequacy in sample size for each item. Items were reduced to fixed number of factors (seven) and the total cumulative variance of seven factors was found $75.62 \%$ ( $>60 \%)$. Although few items cross loaded across components, a cross loading of less than 0.02 was not considered as cross loading. Communalities of less than 0.3 and factor loading of less than 0.4 was ignored. The rotated component matrix table (Varimax rotation) is shown in Appendix B along with scale reliability (Cronbach's alpha) meas- 
ures for each construct and decision taken based on deletion of item to improve reliability. Confirmatory factor Analysis (CFA) was not done. The components/factors identified above as conceived by Authors are represented as Figure 1.

\subsection{Stage-2: Analysis}

In second stage of the study, a group of seasoned entrepreneurs were approached for qualitative data reduction of seven components (thirty five items) so as to make it more pragmatic and avoid duplication. The purification of items was done qualitatively so that a practitioner's perspective and face validity can be assured. The iterative process reduced it to four actionable/measurable components (with nine items). These findings were again tested through Principal Component Analysis (PCA) by an online survey with $n=150$. The items used in the survey instrument were prepared on a 5 point Likert scale. The Cronbach's alpha for internal consistency which was found above 0.7, and Bartlett's Test of Sphericity value suggested for factor analytic model. All the items having communalities of 0.3 and above were selected. The nine different variables (Appendix C) as identified above were loaded onto a four-factor (Appendix D) structure with a cumulative variance explained at $80.20 \%(>60 \%)$. The rotated component matrix grouped the variables into four factors. The factor loading threshold was taken as 0.6 and above. The lower loadings have been suppressed by the package SPSS 20.0. The details of finding are presented in Appendix C \& Appendix D.

\section{Multi-Criterion}

With the items obtained from Exploratory Factor Analysis (via PCA) as in Appendix C, four different factor groups (called "Criteria") were found and named as following. The word "factor" \& "criteria" are interchangeably used. Similarly words like "variable" and "item" are synonymously used.

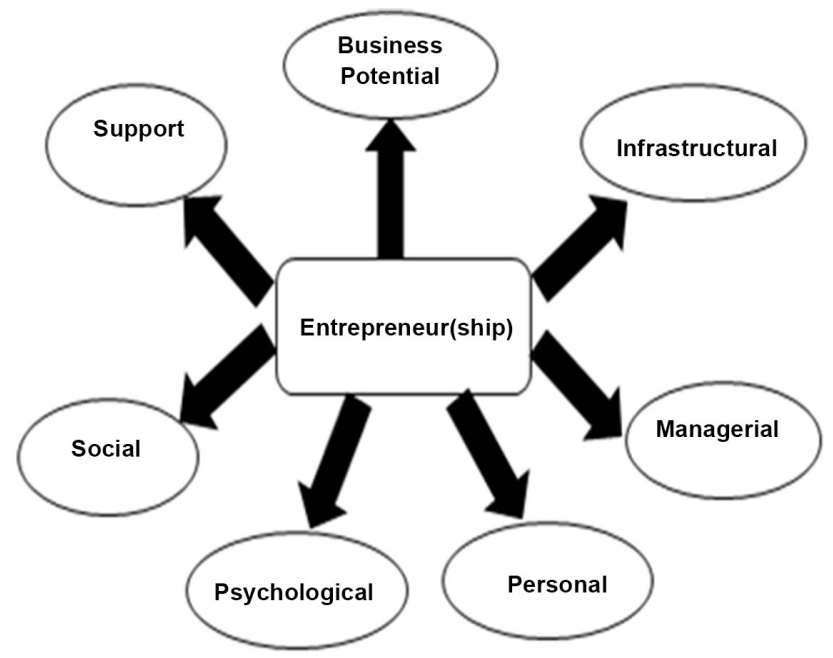

Figure 1. Entrepreneurial factors. 
1). Spark (Variable No. 1;2);

2) Tradeoff (Variable No. 3; 8);

3). Flexibility (Variable No. 6; 7);

4) Drive (Variable No. 4; 5; 9).

The factor naming has lexical connotation derived from the variables/items under them. E.g. "Greater Amount of Capital" and "Cooperation among members" together are seen to be sufficient to create a "Spark" in young mind to venture into entrepreneurship. Similarly, "Ease of Doing Business" and "Level of Liability \& Risk" are seen to be something like risk-return "Tradeoff". "Degree of exit barriers" and "Interpersonal Dimensions" are combined to be seen as "Flexibility", which ensures the easy-going attitude of the young entrepreneur about the exit norms and the peer group cooperation. Likewise, "Governmental Support", "Degree of entry barriers" and "Internal Motivational drive to start" can be together named as "Drive".

\section{Alternatives}

Any business entrepreneur looks for opportunity in a space which is less crowded and is less competitive. An easy withdrawal should ideally be possible in case of turbulence in such venture. Strategically every sunrise industry or business domain is not always conducive. Thus, high entry barrier creates filter for only strong and selective firms to enter and remain in the competition. This helps competition remain healthier and stronger. A low exit barrier many a time depends upon politico-legal environment and the economy at large. From antecedents of an entrepreneurial career, four options can be segregated out for a budding entrepreneur to articulate before undertaking a venture. Modeling the strategic choices (called alternatives) across a $2 \times 2$ matrix (Table 1), i.e. across low and high range of entry and exit barriers-an entrepreneur can assess potential of his idea. For the suggested Analytics Hierarchy process (AHP) based Multi-criteria decision making model (MDSS) these options are considered as alternatives/variants.

The theoretical model with AHP (Figure 2) having Scenario = 1, Criteria $=4$, Alternatives/Variants $=4$, is shown.

\section{AHP Output (Excel Screen)}

The multi criteria decision making (MCDM) is called Analytic Hierarchy Process (AHP) in short and is a tool used for Decision Support System. The determination of criteria and alternatives (Table 2) are very subjective as found above.

\section{Criterion Comparison}

Comparative values were entered only in the upper triangle for pairwise comparison. Lower triangle values are reciprocal to corresponding values in upper triangle. If one more important than the other values from 2 to 9 entered; and if 
Table 1. $2 \times 2$ Design of alternatives ( 4 No.).

\begin{tabular}{cccc}
\hline \multicolumn{2}{c}{ Variants: Barriers $(2 \times 2)$} & \multicolumn{2}{c}{ Entry } \\
\hline & & Low & High \\
\hline \multirow{2}{*}{ Exit } & Low & L; L & H; L \\
& High & L; H & H; H \\
\hline
\end{tabular}

The researchers have coded the four above strategic alternatives as: L, L: Ignore; L, H: Trap; H, L: Focus; H, $\mathrm{H}$ : Intense.

Table 2. MCDM model (Defining Criteria-Alternatives).

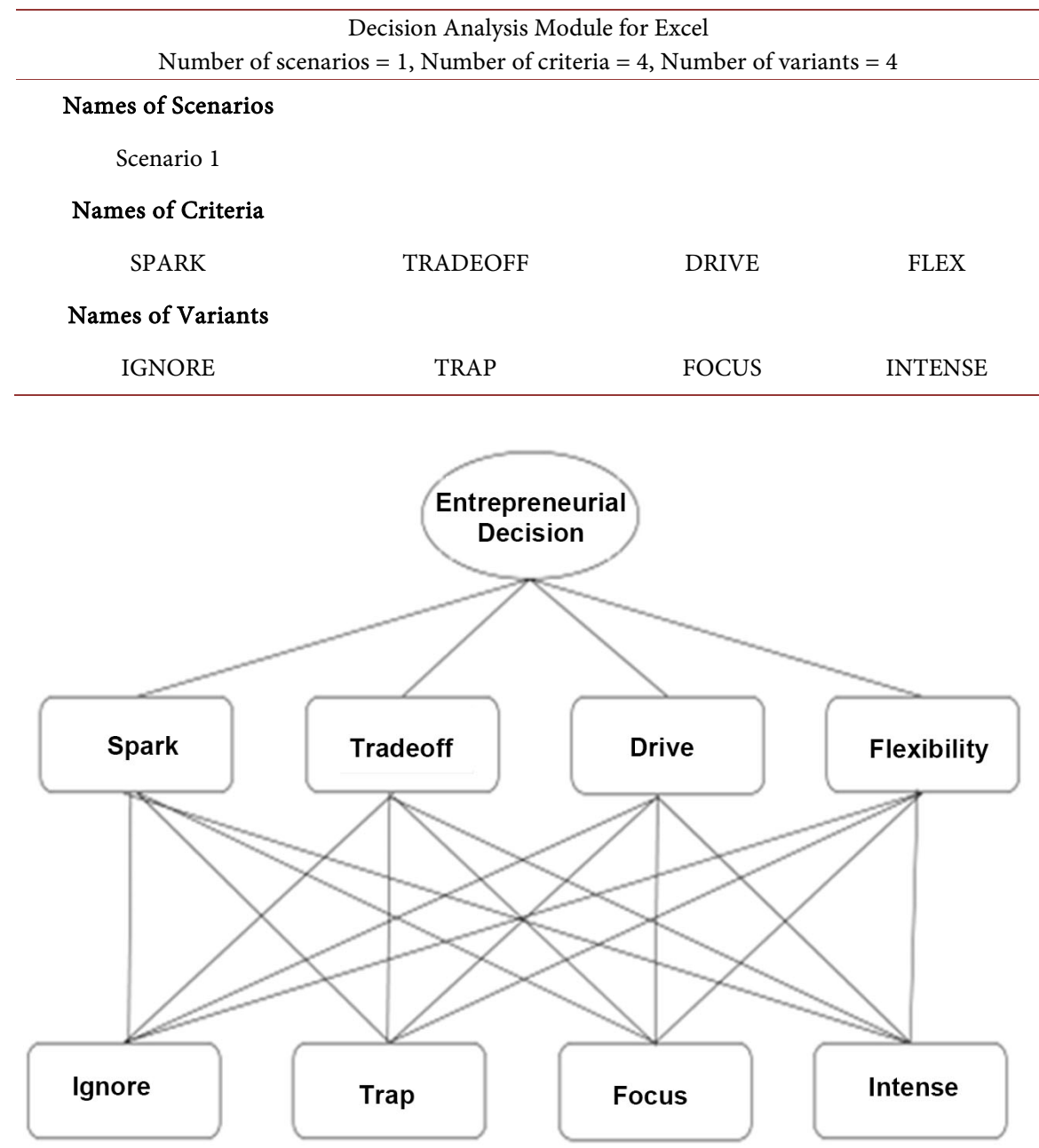

Figure 2. Theoretical AHP model.

less values from $1 / 2$ to $1 / 9$. For equality, either no value is entered or value entered is 1 . Inconsistency index should be $<0.1$, and if greater, the comparison is revised by re-approaching the respondent. Another output table shows calculated weights of each criterion or variant based on a geometric mean method. Total evaluation of variants or alternatives is the final outcome of this analysis. In this paper, authors have done pair wise comparison. The four criteria (Spark; Tradeoff; Drive; Flex) were subject to pair wise comparison only in the upper 
triangle, as the values in the lower triangle are reciprocal. In a $4 \times 4$ reciprocal matrix of paired comparison we sum each column of the matrix, then divide each element with sum of the respective column to find normalized weight. Column total becomes 1 . The averaging across rows gives normalized principal eigen vector. Criteria Weights (Wi) is representative of Priority vector or normalized principal eigen vector and gives relative weights among criterions and their ranking (See: Table 3). The consistency of the response in scenario-1 can be checked by finding principal eigen value. This is found by:

Consistency Index (CI) [49] as per Prof. Saaty [50] is a deviation or degree of consistency found by: ( $n=$ size of comparison matrix)

$$
C I=\left(\sum-n\right) /(n-1)
$$

Thus in this case, $C I=(4.243797869-4) / 3=0.081265956$.

The above output shows (scenario $=1$, i.e. one user respondent scenario) comparison of individual criterion using pairwise comparison matrix with elements saying how much more important is criterion in the row than the criterion in the column. The inconsistency index is $0.0813(<0.1)$, and hence the pairwise comparisons are consistent. In extreme right column calculated weights \& ranks of individual criteria is shown.

Prof.Saaty [50] has calculated appropriate consistency index, called Random Consistency Index $(R I)$ [49], which is 0.9 for $n=4$.

Consistency Ratio $(C R)=C I / R I=0.090295507=9 \%(<10 \%)$.

$C R$ assesses if the subjective evaluation is consistent. In this case it is consistent.

Thus, preference wise, TRADEOFF $>$ FLEX $>$ SPARK $>$ DRIVE.

\section{Alternative-Comparison: Criterion-1}

Evaluation of variants (or alternatives) is done according to individual criteria one by one on pair-wise comparison method. This is because the criteria are relative and not continuous data. AHP process can thus continue for paired comparison of alternatives on each of the criterion. Evaluation of variants on SPARK is given in Table 4.

Table 3. Comparison for criterions.

\begin{tabular}{ccccccc}
\hline & SPARK & TRADEOFF & DRIVE & FLEX & Criteria Weights (Wi) & Rank \\
\hline SPARK & 1 & 0.50 & 3 & 0.25 & 0.163212 & 3 \\
TRADEOFF & 2.00 & 1 & 6 & 2 & 0.433566 & 1 \\
DRIVE & 0.33333 & 0.1666667 & 1 & 0.25 & 0.066309 & 4 \\
FLEX & 4 & 0.5 & 4 & 1 & 0.336913 & 2 \\
SUM & 7.33333 & 2.1666667 & 14 & 3.5 & 1 & \\
\hline
\end{tabular}

$\Sigma($ each element of eigen vector $) \times($ Sum of columns of reciprocal matrix $)=(7.33333 \times 0.163212)+$ $(2.1666667 \times 0.433566)+(14 \times 0.066309)+(3.5 \times 0.336913)=4.243797869$. 
Table 4. Evaluation of variants according to SPARK.

\begin{tabular}{ccccccc}
\hline SPARK & IGNORE & TRAP & FOCUS & INTENSE & Variants Weights & Rank \\
\hline IGNORE & 1 & 2.00 & 0.25 & 0.333333 & 0.126337 & 3 \\
TRAP & 0.50 & 1 & 0.2 & 0.333333 & 0.081551 & 4 \\
FOCUS & 4 & 5 & 1 & 4 & 0.554813 & 1 \\
INTENSE & 3 & 3 & 0.25 & 1 & 0.237299 & 2 \\
SUM & 8.5 & 11 & 1.7 & 5.666667 & 1 & \\
\hline
\end{tabular}

$\Sigma=4.258801248 ; C I=0.086267083(<0.1) ; R I=0.9 ; C R=0.095852314(<10 \%) ;$ Based on Spark (Greater Amount of Capital; Cooperation among members), the preferred alternatives are: FOCUS > INTENSE > IGNORE $>$ TRAP.

The ignition system of an entrepreneur is mainly kick started by a highly supportive close network, both in terms of financial capital and cooperative capital.

\subsection{Alternative-Comparison: Criterion-2}

From Table 5 showing evaluation of variants on TRADEOFF, it can be seen that if the incumbent believes that the risk and liability or the cost-benefit scenario is manageable within controllable contours, one can even stay ready for an intense competition.

\subsection{Alternative-Comparison: Criterion-3}

Table 6 showing evaluation of variants on DRIVE indicates that an irrational inner drive of an entrepreneur just by looking at lucrative offer and support system, ease of entry and emotional attachment to a business idea may land up her in trouble. Thus a focus seems a better option.

\subsection{Alternative-Comparison: Criterion-4}

In Table 7 from evaluation of variants on FLEXIBILITY, it can be interpreted that if there is a peer support and mutual cooperation existing in the system it helps one build upon an idea quickly or ignore it at first instance if there is none.

\section{Criterion Weights:}

From Priority Vector (criterion-comparison matrix) obtained from Section 6, the criterion weights are shown in Table 8.

Based on the aggregate weight of three criteria (after ignoring that of "Drive"), the Adjusted weight for all three criteria were found as given below. The priority vector of each alternative or variant, called "variant weight" is listed under its corresponding criterion. The composite weight of each alternative is summation of products of the variant weight $\&$ corresponding adjusted weight of each criterion. Basing this calculation a final ranking of alternative choices is drawn.

In the matrix given in Table 9 for Composite Weights \& Rank of variants, weights of all variants (rows) according to four individual criteria (columns) are calculated.

All the pairwise comparison matrices on four criteria e.g. Spark, Tradeoff, 
Table 5. Evaluation of variants according to TRADEOFF.

\begin{tabular}{ccccccc}
\hline TRADEOFF & IGNORE & TRAP & FOCUS & INTENSE & Variants Weights & Rank \\
\hline IGNORE & 1 & 2.00 & 0.333333 & 0.333333 & 0.137325 & 3 \\
TRAP & 0.50 & 1 & 0.166667 & 0.333333 & 0.076015 & 4 \\
FOCUS & 3 & 6 & 1 & 4 & 0.544328 & 1 \\
INTENSE & 3 & 3 & 0.25 & 1 & 0.242332 & 2 \\
SUM & 7.5 & 12 & 1.75 & 5.666667 & 1 & \\
\hline
\end{tabular}

$\Sigma=4.267909664 ; C I=0.089303221(<0.1) ; R I=0.9 ; C R=0.099225801(<10 \%) ;$ Based on Tradeoff (Ease of Doing Business; Level of Liability \& Risk), the preferred alternatives are: FOCUS > INTENSE > IGNORE $>$ TRAP.

Table 6. Evaluation of variants according to DRIVE.

\begin{tabular}{ccccccc}
\hline DRIVE & IGNORE & TRAP & FOCUS & INTENSE & Variants Weights & Rank \\
\hline IGNORE & 1 & 0.13 & 0.2 & 0.333333 & 0.052526 & 4 \\
TRAP & 8.00 & 1 & 3 & 6 & 0.572385 & 1 \\
FOCUS & 5 & 0.3333333 & 1 & 4 & 0.269227 & 2 \\
INTENSE & 3 & 0.1666667 & 0.25 & 1 & 0.105862 & 3 \\
SUM & 17 & 1.625 & 4.45 & 11.33333 & 1 & \\
\hline
\end{tabular}

$\Sigma=4.220893107 ; C I=0.073631036(<0.1) ; R I=0.9 ; C R=0.081812262(<10 \%) ;$ Based on Drive (Governmental Support; Degree of entry barriers; Internal Motivational drive to start), the preferred alternatives are: TRAP $>$ FOCUS $>$ INTENSE $>$ IGNORE.

Table 7. Evaluation of variants according to FLEXIBILITY.

\begin{tabular}{ccccccc}
\hline FLEX & IGNORE & TRAP & FOCUS & INTENSE & Variants Weights & Rank \\
\hline IGNORE & 1 & 3.00 & 0.333333 & 2 & 0.212046 & 2 \\
TRAP & 0.33 & 1 & 0.142857 & 0.25 & 0.062791 & 4 \\
FOCUS & 3 & 7 & 1 & 5 & 0.572502 & 1 \\
INTENSE & 0.5 & 4 & 0.2 & 1 & 0.152661 & 3 \\
SUM & 4.83333 & 15 & 1.67619 & 8.25 & 1 & \\
\hline
\end{tabular}

$\Sigma=4.185826997 ; C I=0.061942332(<0.1) ; R I=0.9 ; C R=0.068824814(<10 \%)$; Based on Flexibility (Degree of exit barriers; Interpersonal Dimensions), the preferred alternatives are: FOCUS > IGNORE $>$ INTENSE $>$ TRAP.

Table 8. Criterion weights.

\begin{tabular}{ccc}
\hline Criterion & Criteria Weights $(\mathrm{Wi})$ & $\%$ \\
\hline SPARK & 0.163212 & 16.32 \\
TRADEOFF & 0.433566 & 43.36 \\
DRIVE $^{*}$ & 0.066309 & 6.63 \\
FLEX & 0.336913 & 33.69 \\
${ }^{*}$ Ignored & Aggregate & 93.37 \\
\hline
\end{tabular}

Drive \& Flexibility are found consistent (all their inconsistency indices are found to be $<10 \%$ or 0.1 ). 
Table 9. Composite weights \& Rank of variants.

\begin{tabular}{ccccccc}
\hline Criterion-> & SPARK & TRADEOFF & DRIVE & FLEX & $\begin{array}{c}\text { Composite } \\
\text { Wt. }\end{array}$ & $\begin{array}{c}\text { Overall } \\
\text { Rank }\end{array}$ \\
\hline Adj. Weight & 0.174803 & 0.4643571 & 0.071018 & 0.36084 & & \\
\hline IGNORE & 12.63 & 13.73 & 5.25 & 21.20 & 16.61 & 3 \\
TRAP & 8.16 & 7.60 & 57.24 & 6.28 & 11.29 & 4 \\
FOCUS & 55.48 & 54.43 & 26.92 & 57.25 & 57.54 & 1 \\
INTENSE & 23.73 & 24.23 & 10.59 & 15.27 & 21.66 & 2 \\
\hline
\end{tabular}

A synthesis of it can be observed in total evaluation of variants in the last output table is shown below in the chart in Figure 3.

\section{Conclusion}

It can be concluded that the best variant is Focus with weight 0.5754 followed by Intense (0.2166), Ignore (0.1661) \& finally, Trap (0.1129) i.e. FOCUS $(\mathrm{H} / \mathrm{L})>$ INTENSE $(\mathrm{H} / \mathrm{H})>\operatorname{IGNORE}(\mathrm{L} / \mathrm{L})>$ TRAP $(\mathrm{L} / \mathrm{H})$. The above ranking is done based on one scenario where an expert respondent's subjective evaluation of criteria and variants has been used. However, multiple scenarios with more respondents taken can improve the findings and final ranking.

\section{Managerial Implication}

The findings suggest that entrepreneurs look for much focused business opportunities where only serious competitors take interest and can overcome entry barriers to get into the business spectrum. However, at the same time they look for safe exit in case of turbulence. As in case of turbulence it may turn out to be a difficult exit which may create a very intense situation in the business. Given these findings, entrepreneurs may prefer to ignore opportunities which don't provide optimal entry and exit conditions. It shows that young millennial Indian entrepreneurs are not risk averse. They are very well risk takers and experimental in seeking opportunities amid healthy and high competition. They don't want to get trapped in a scenario where they get into a business so lucrative at the first instance but difficult to liquidate or wind up.

In case of a budding entrepreneur, the risk taking ability depends on situation she is facing. But many a time, due to turbulence in the socio-economic environment the appetite decreases and finally diminishes to perish. The findings from the above analysis suggest that Focus is a strategic option when the barriers to entry are higher and very select competitors can get into the spectrum. This advocates for resource constraints and core competencies within an individu$\mathrm{al} /$ firm. This is better coupled with a low exit barrier where there happens to exist a fail-safe and fast exit plan.

\section{Limitations}

The confirmatory factor analysis (CFA), validity checks (Convergent \& Discriminant), and model fit indices have not being checked after the items were 


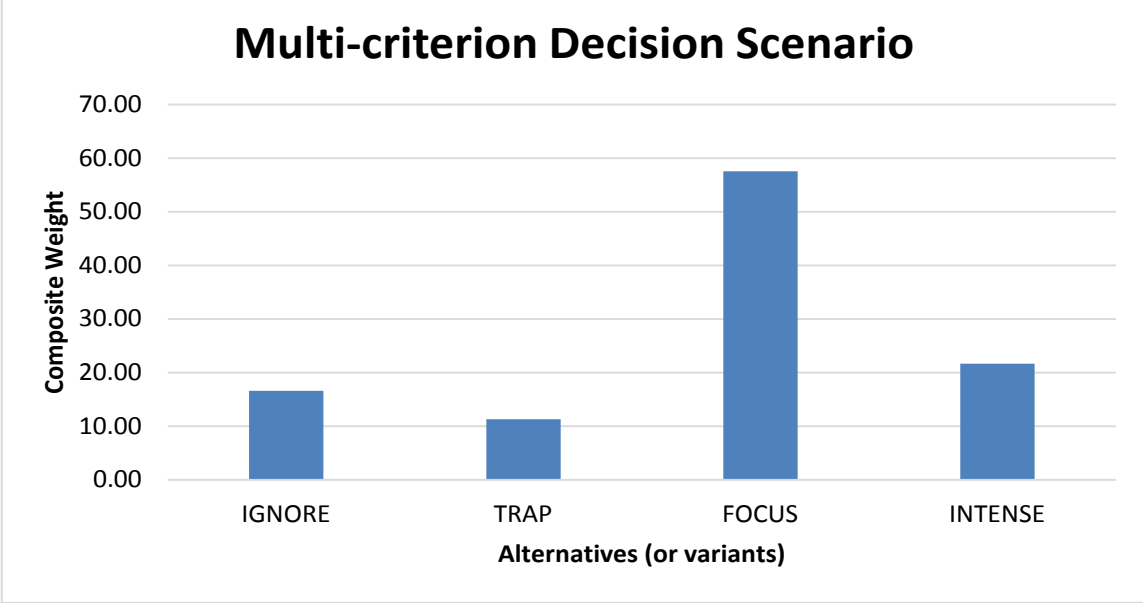

Figure 3. Comparative chart of variants.

reduced to seven and the four factors. This is a limitation of the current study and is future scope of research. The above four-factor multi-criterion model was checked only using one scenario (i.e. one decision maker) through Analytic Hierarchy Process (AHP) enabled through DAME add-in in MS-Excel package. The same can be done with multiple decision makers to remove possible bias.

\section{Conflicts of Interest}

The authors declare no conflicts of interest regarding the publication of this paper.

\section{References}

[1] http://www.india.gov.in/people-groups/community/entrepreneur

[2] http://www.livemint.com/Opinion/Eo1PgYgUyKl9xgWLrLPwJP/Demographic-divi dend-growth-and-jobs.html

[3] https://www.pwc.in/publications/2017/vision-2025-unlocking-indias-potential-for-1 eadership-in-pharmaceutical-innovation.html

[4] http://www.startupindia.gov.in/content/sih/en/home-page.html

[5] https://t-hub.co,www.startupindia.gov.in/registration.php

[6] https://www.ges2017.org/govt-of-india-support-for-entrepreneurs

[7] https://www.zdnet.com/article/there-are-six-types-of-startups

[8] Gürol and Atsan (2006) Entrepreneurial Characteristics amongst University Students: Some Insights for Entrepreneurship Education and Training in Turkey. Education and Training, 48, 25-38. https://doi.org/10.1108/00400910610645716

[9] Bolton and Thompson (2000) Entrepreneurs: Talent, Temperament, Technique. Butterworth Heinemann, Oxford.

[10] Thompson, J. and Downing, R. (2007) The Entrepreneur Enabler: Identifying and Supporting Those with Potential. Journal of Small Business and Enterprise Development, 14, 528-544. https://doi.org/10.1108/14626000710773592

[11] Venkatapathy, R. (1986) First and Second Generation Entrepreneurial Types. Journal of Social Behavior and Personality, 1, 471-472. 
[12] Fraboni and Saltstone (1990) The Entrepreneurial Personality in Relation to Holland's Occupational Types. Journal of Small Business \& Entrepreneurship, 7, 23-28. https://doi.org/10.1080/08276331.1990.10600357

[13] Giorgi, L. and Marsh, C. (1990) The Protestant Work Ethic as a Cultural Phenomenon. European Journal of Social Psychology, 20, 499-518. https://doi.org/10.1002/ejsp.2420200605

[14] Furnham, A. (1986) Economic Locus of Control. Human Relations, 39, 29-43. https://doi.org/10.1177/001872678603900102

[15] Winfield, I. (1984) People in Business. Heinemann, London.

[16] Chell, E. (1986) The Entrepreneurial Personality: A Review and Some Theoretical Developments. In: Curran, J., Stanworth, J. and Watkins, D., Eds., The Survival of the Small Firm, Gower, Aldershot, 1.

[17] Fagenson, E. (1993) Personal Value Systems of Men and Women Entrepreneurs Managers. Journal of Business Venturing, 8, 409-430. https://doi.org/10.1016/0883-9026(93)90022-W

[18] Cassidy and Lynn (1989) A Multifactorial Approach to Achievement Motivation. Journal of Occupational Psychology, 62, 301-312. https://doi.org/10.1037/t07252-000

[19] Markman, G. and Baron, R. (2003) Person-Entrepreneurship Fit: Why Some People Are More Successful as Entrepreneurs than Others. Human Resource Management Review, 13, 281-301. https://doi.org/10.1016/S1053-4822(03)00018-4

[20] McClelland, D.C. (1961) The Achieving Society. Van Nostrand, Princeton. https://doi.org/10.1037/14359-000

[21] McClelland, D.C. (1987) Characteristics of Successful Entrepreneurs. Journal of Creative Behavior, 21, 219-233. https://doi.org/10.1002/j.2162-6057.1987.tb00479.x

[22] Koh, H.C. (1996) Testing Hypotheses of Entrepreneurial Characteristics: A Study of Hong Kong MBA Students. Journal of Managerial Psychology, 11, 12-25. https://doi.org/10.1108/02683949610113566

[23] Tajeddini \& Mueller (2009) Entrepreneurial Characteristics in Switzerland and the UK: A Comparative Study of Techno-Entrepreneurs. Journal of International Entrepreneurship, 7, 1-25. https://doi.org/10.1007/s10843-008-0028-4

[24] Mueller (2004) Gender Gaps in Potential for Entrepreneurship across Countries and Cultures. Journal of Developmental Entrepreneurship, 9, 199-220.

[25] Liles, P.R. (1981) Who Are the Entrepreneurs? In: Gorb, P., Dowell, P. and Wilson, P., Eds., Small Business Perspectives, Armstrong Publishing, London Business School, London, 33-50.

[26] Hisrich, R. and Brush, C. (2009) The Woman Entrepreneur: Management Skills and Business Problems. ERPN: Human Capital (Sub-Topic), 22.

[27] Hatak, et al. (2015) Age, Job Identification, and Entrepreneurial Intention. Journal of Managerial Psychology, 30, 38-53. https://doi.org/10.1108/JMP-07-2014-0213

[28] Fung, H.H., Lai, P. and Ng, R. (2001) Age Differences in Social Preferences among Taiwanese and Mainland Chinese: The Role of Perceived Time. Psychology and Aging, 16, 351-356. https://doi.org/10.1037/0882-7974.16.2.351

[29] Deakins, D. and Freel, M. (2009) Entrepreneurship and Small Firms. 5th Edition, McGraw Hill, New York.

[30] Mahadea, D. (2001) Similarities and Differences between Male and Female Entrepreneurial Attributes in Manufacturing Firms in the Informal Sector in the Trans- 
kei. Development Southern Africa, 18, 189-197.

https://doi.org/10.1080/037/68350120041893

[31] Entrialgo, M., Fernández, E. and Vázquez, C.J. (2000) Linking Entrepreneurship and Strategic Management: Evidence from Spanish SMEs. Technovation, 20, 427-436. https://doi.org/10.1016/S0166-4972(99)00168-6

[32] Cromie, S. (2000) Assessing Entrepreneurial Implications: Some Approaches and Empirical Evidence. European Journal of Work and Organisational Psychology, 9, 7-30. https://doi.org/10.1080/135943200398030

[33] Littunen, H. (2000) Entrepreneurship and the Characteristics of the Entrepreneurial Personality. International Journal of Entrepreneurial Behavior \& Research, 6, 295-310. https://doi.org/10.1108/13552550010362741

[34] Kristiansen, S. and Indarti, N. (2004) Entrepreneurial Intention among Indonesian and Norwegian Students. Journal of Enterprising Culture, 12, 55-78. https://doi.org/10.1142/S021849580400004X

[35] Krueger Jr., N.F., Reilly, M.D. and Carsrud, A.L. (2000) Competing Models of Entrepreneurial Intentions. Journal of Business Venturing, 15, 411-432. https://doi.org/10.1016/S0883-9026(98)00033-0

[36] Keeley, et al. (2001) Entrepreneurial Intent among Students in Scandinavia and in the USA. Enterprise and Innovation Management Studies, 2, 145-160. https://doi.org/10.1080/14632440110094632

[37] de Wit, G. and van Winden, F.A.A.M. (1989) An Empirical Analysis of Self-Employment in the Netherlands. Small Business Economics, 1, 263-272. https://doi.org/10.1007/BF00393805

[38] Taylor, M.P. (1996) Earnings, Independence or Unemployment: Why Become Self-Employed? Oxford Bulletin of Economics and Statistics, 58, 253-266. https://doi.org/10.1111/j.1468-0084.1996.mp58002003.x

[39] Crant, J.M. (1996) The Proactive Personality Scale as a Predictor of Entrepreneurial Intentions. Journal of Small Business Management, 34, 42-49.

[40] Dolton, P.J. and Makepeace, G.H. (1990) Self-Employment among Graduates. Bulletin of Economic Research, 42, 35-54. https://doi.org/10.1111/j.1467-8586.1990.tb00290.x

[41] Evans, D. and Leighton, L.S. (1989) Some Empirical Aspects of Entrepreneurship. American Economic Review, 79, 519-535. https://doi.org/10.1007/978-94-015-7854-7_6

[42] Gibb, A. and Ritchie, J. (1981) Influences on Entrepreneurship: A Study over Time-In Bolton Ten Years On-. Proceedings of the UK Small Business Research Conference, Polytechnic of Central London, 20-21.

[43] Miller, D. and Friesen, P.H. (1982) Innovation in Conservative and Entrepreneurial Firms: Two Models of Strategic Momentum. Strategic Management Journal, 3, 1-25. https://doi.org/10.1002/smj.4250030102

[44] Rotter, J.B. (1954) Social Learning and Clinical Psychology. Prentice Hall, Englewood Cliffs. https://doi.org/10.1037/10788-000

[45] Teknomo, K. (2006) Analytic Hierarchy Process (AHP) Tutorial. http://people.revoledu.com/kardi/tutorial/AHP

[46] Perzina, R. and Jaroslav Ramík, J. (2014) Microsoft Excel as a Tool for Solving Multicriteria Decision Problems. Procedia Computer Science, 35, 1455-1463. https://doi.org/10.1016/j.procs.2014.08.206

[47] The Venture Must Fall in the Definitional Purview of Startup India. 
http://www.startupindia.gov.in/content/sih/en/home-page.html

[48] Gibbs, G.R. (2007) Thematic Coding and Categorizing. In: Gibbs, G.R., Ed., Analyzing Qualitative Data, SAGE Publications, Thousand Oaks, Ch. 4.

https://doi.org/10.4135/9781849208574.n4

[49] https://people.revoledu.com/kardi/tutorial/AHP/Consistency.htm

[50] Saaty, T.L. (1994) Fundamentals of Decision Making and Priority Theory with the Analytic Hierarchy Process. RWS Publications, Pittsburgh.

\section{Abbreviations}

AHP: Analytic Hierarchy Process

AICs: Atal Incubation Centres

AIM: Atal Innovation Mission

ATL: Atal Tinkering Labs

BIRAC: Biotechnology Industry Research Assistance Council

CFA: Confirmatory Factor Analysis

DAME: Decision Analysis Module for Excel

EFA: Exploratory Factor Analysis

FGD: Focus Group Discussion

GOI: Government of India

MCDM: The Multi Criteria Decision Making

MDSS: Multi-Criteria Decision Making Model

PCA: Principal Component Analysis

PMKVY: Pradhan Mantri Kaushal Vikas Yojana

SEED: Science for Equity Empowerment and Development

STEP: Support to Training and Employment Programme for Women

TREAD: Trade Related Entrepreneurship Assistance and Development 


\section{Appendix}

Appendix A. Comprehensive list of codes \& categories $(n=8)$.

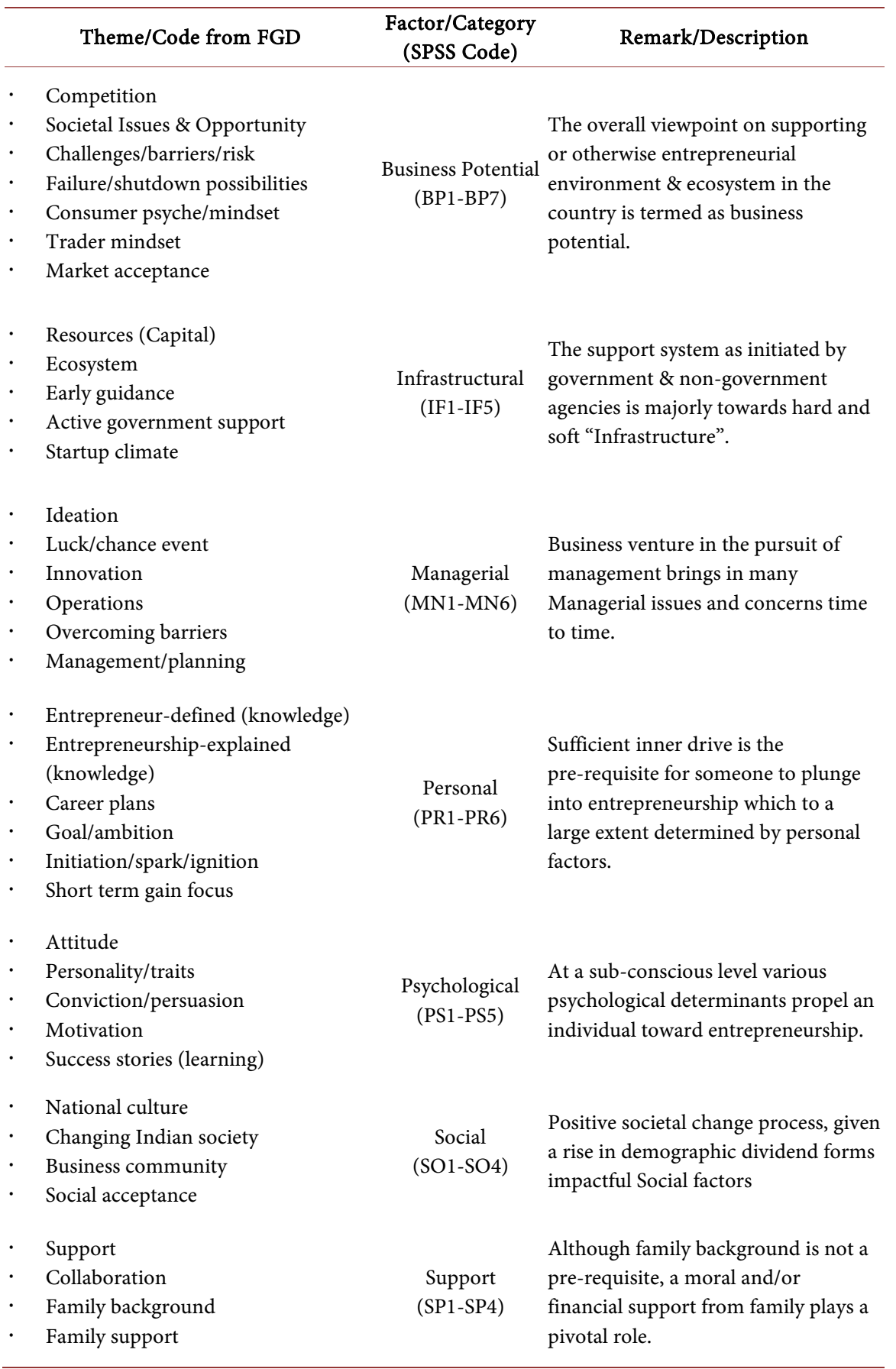


Appendix B. Rotated component matrix \& scale reliability $(n=290)$.

\begin{tabular}{|c|c|c|c|c|c|}
\hline Component & Items & Loadings & $\begin{array}{c}\text { Cronbach's } \\
\text { Alpha }\end{array}$ & $\begin{array}{l}\text { Cronbach's Alpha if } \\
\text { Item Deleted }\end{array}$ & Decision to drop item \\
\hline \multirow{7}{*}{1} & BP4 & 0.861 & \multirow{7}{*}{0.960} & \multirow{7}{*}{ no improvement } & \multirow{7}{*}{ nil } \\
\hline & BP3 & 0.859 & & & \\
\hline & BP5 & 0.831 & & & \\
\hline & BP6 & 0.822 & & & \\
\hline & BP7 & 0.802 & & & \\
\hline & BP2 & 0.755 & & & \\
\hline & BP1 & 0.731 & & & \\
\hline \multirow{4}{*}{2} & $\mathrm{SO} 1$ & 0.829 & \multirow{4}{*}{0.932} & \multirow{4}{*}{ no improvement } & \multirow{4}{*}{ nil } \\
\hline & $\mathrm{SO} 3$ & 0.812 & & & \\
\hline & $\mathrm{SO} 4$ & 0.797 & & & \\
\hline & $\mathrm{SO} 2$ & 0.793 & & & \\
\hline \multirow{5}{*}{3} & IF4 & 0.785 & \multirow{5}{*}{0.875} & \multirow{5}{*}{ no improvement } & \multirow{5}{*}{ nil } \\
\hline & IF5 & 0.751 & & & \\
\hline & IF3 & 0.750 & & & \\
\hline & IF2 & 0.718 & & & \\
\hline & IF1 & 0.704 & & & \\
\hline \multirow{6}{*}{4} & MN4 & 0.762 & \multirow{6}{*}{0.879} & \multirow{6}{*}{00.879 (if MN3 deleted) } & \multirow{6}{*}{ nil } \\
\hline & MN5 & 0.729 & & & \\
\hline & MN6 & 0.655 & & & \\
\hline & MN3 & 0.578 & & & \\
\hline & MN2 & 0.548 & & & \\
\hline & MN1 & 0.524 & & & \\
\hline \multirow{5}{*}{5} & PS3 & 0.786 & \multirow{5}{*}{0.931} & \multirow{5}{*}{00.951 (if PS5 deleted) } & \multirow{5}{*}{$\begin{array}{l}\text { PS5 (Family } \\
\text { Background) }\end{array}$} \\
\hline & PS2 & 0.784 & & & \\
\hline & PS1 & 0.771 & & & \\
\hline & PS4 & 0.732 & & & \\
\hline & PS5 & 0.454 & & & \\
\hline \multirow{4}{*}{6} & SP2 & 0.798 & \multirow{4}{*}{0.896} & \multirow{4}{*}{00.900 (if SP3 deleted) } & \multirow{4}{*}{$\begin{array}{c}\text { SP3 (Success } \\
\text { Stories-learning) }\end{array}$} \\
\hline & SP1 & 0.790 & & & \\
\hline & SP4 & 0.688 & & & \\
\hline & SP3 & 0.565 & & & \\
\hline \multirow{6}{*}{7} & PR2 & 0.747 & \multirow{6}{*}{0.900} & \multirow{6}{*}{ no improvement } & \\
\hline & PR3 & 0.707 & & & \\
\hline & PR6 & 0.508 & & & \\
\hline & PR4 & 0.503 & & & nil \\
\hline & PR1 & 0.459 & & & \\
\hline & PR5 & 0.427 & & & \\
\hline
\end{tabular}


Appendix C. Practitioners' perspectives.

\begin{tabular}{lc}
\hline 1 & Greater Amount of Capital \\
\hline 2 & Cooperation among members \\
3 & Ease of doing business \\
4 & Governmental Support \\
5 & Degree of entry barriers \\
6 & Degree of exit barriers \\
7 & Interpersonal dimensions \\
8 & Level of liability \& risk \\
9 & Internal motivational drive to start \\
\hline
\end{tabular}

Appendix D. Grouping of items into components.

\begin{tabular}{ccc}
\hline Component & Item & Loading \\
\hline \multirow{2}{*}{1} & Greater amount of capital & 0.919 \\
& Cooperation among members & 0.914 \\
2 & Ease of doing business & 0.997 \\
& Level of liability \& risk & 0.997 \\
3 & Degree of exit barriers & 0.937 \\
& Interpersonal dimensions & 0.938 \\
& Internal motivational drive to start & 0.847 \\
& Governmental support & 0.897 \\
& Degree of entry barriers & 0.679 \\
\hline
\end{tabular}

\section{Other Website Reference}

http://www.preservearticles.com/2012022923838/what-are-the-different-types-o f-cooperative-societies.html http://www.yourarticlelibrary.com/business/cooperative/cooperative-organisatio n-definition-characteristics-and-types/75888

http://www.yourarticlelibrary.com/society/top-3-major-types-of-cooperative-soc ieties/32001

https://archive.india.gov.in/business/starting_business/co_operatives.php https://archive.india.gov.in/citizen/co_operatives/co_operatives.php?id=5 https://archive.india.gov.in/citizen/co_operatives/co_operatives.php?id=3 https://en.wikipedia.org/wiki/Cooperative_movement_in_India https://www.ges2017.org/govt-of-india-support-for-entrepreneurs/ 